\title{
Development of loop-mediated isothermal amplification (LAMP) for simple detection of Leishmania infection
}

\author{
Chaichontat Sriworarat ${ }^{1}$, Atchara Phumee ${ }^{2}$, Mathirut Mungthin ${ }^{3}$, Saovanee Leelayoova ${ }^{3}$ and Padet Siriyasatien ${ }^{24^{*}}$ (D)
}

\begin{abstract}
Background: Leishmaniasis is a neglected tropical disease that is caused by an obligate intracellular protozoan of the genus Leishmania. Recently, an increasing number of autochthonous leishmaniasis cases caused by L. martiniquensis and the novel species $L$. siamensis have been described in Thailand, rendering an accurate diagnosis of this disease critical. However, only a few laboratories are capable of diagnosing leishmaniasis in Thailand. To expand leishmaniasis diagnostic capabilities, we developed a simple colorimetric loop-mediated isothermal amplification (LAMP) technique for the direct detection of Leishmania DNA.
\end{abstract}

Methods: LAMP was performed for 75 min using four primers targeting the conserved region of the 185 ribosomal RNA gene, and the DNA indicator used was malachite green (MG). To simulate crude samples, cultured promastigotes of L. siamensis were mixed with blood or saliva. Also, clinical samples (blood, saliva, and tissue biopsies) were obtained from patients with cutaneous leishmaniasis (CL) and visceral leishmaniasis (VL). All samples were boiled for 10 min and introduced directly into the LAMP reaction mixture without DNA purification.

Results: The use of MG resulted in an unambiguous differentiation of positive and negative controls. For L. siamensis, the detection limit was $10^{3}$ parasites $/ \mathrm{mL}$ or 2.5 parasites/tube. Saliva, tissue biopsies, and whole blood were indicative of active Leishmania infection, and their direct usages did not adversely affect the detection limit. In addition, this LAMP assay could detect DNA from multiple Leishmania species other than L. siamensis and L. martiniquensis, including L. aethiopica, L. braziliensis, L. donovani and L. tropica.

Conclusions: The simplicity and sensitivity of LAMP in detecting active Leishmania infection could enable the rapid diagnosis of leishmaniasis, thereby facilitating the survey and control of leishmaniasis in Thailand. However, our limited number of samples warranted a further validation with a larger cohort of patients before this assay could be deployed.

Keywords: Leishmania martiniquensis, L. siamensis, LAMP, Malachite green, Diagnosis

\section{Background}

Causing more than 50,000 deaths annually [1], leishmaniasis is one of the most debilitating poverty-related diseases and presents a severe threat to socioeconomic development. This disease is caused by more than 20 species of the obligate intracellular protozoa Leishmania [2]. These are transmitted to humans through the bites of female sand flies [1]. Upon infection, three main

\footnotetext{
* Correspondence: padet.s@chula.ac.th

${ }^{2}$ Department of Parasitology, Faculty of Medicine, Chulalongkorn University, Bangkok 10330, Thailand

${ }^{4}$ Excellence Center for Emerging Infectious Diseases, King Chulalongkorn Memorial Hospital, Thai Red Cross Society, Bangkok 10330, Thailand

Full list of author information is available at the end of the article
}

clinical forms can be recognized: cutaneous leishmaniasis (CL), mucocutaneous leishmaniasis (MCL), and visceral leishmaniasis (VL). CL, the most common form, is characterized by the presence of various ulcerative lesions, which lead to disfiguring and/or disabling scars $[3,4]$. Consequently, patients with CL often live in obscurity [5], thereby preventing expeditious treatment and increasing the probability of transmission. MCL is described by a severe destruction of mucosal regions (nose, mouth, and throat) [4]. VL is an infection of the internal organs that is characterized by prolonged fever, anemia, hepatosplenomegaly, and weight loss. VL is fatal if left untreated [6]. 
Since the first case report in 1996 [7], indigenous leishmaniasis has been increasingly prevalent in Thailand, especially in HIV patients. Case reports include both VL [7-12] and $C L[10,11,13-15]$ and are concentrated in the northern and southern part of Thailand. In contrast to other regions in Asia, most cases in Thailand are caused by either L. martiniquensis or L. siamensis $[12,16]$. As early detection is one of the most important aspects of disease containment, the need for a robust and rapid diagnostic method has never been higher. To summarize, currently available methods can be divided into three groups: parasitological methods, serological methods, and molecular methods, each of which presents various advantages and disadvantages.

Parasitological methods, which include microscopy and parasite culturing, have been considered the gold standard in diagnosing leishmaniasis. In Thailand, however, only a handful of laboratories could culture parasites. Also, serological diagnostic methods with comparable sensitivity to parasitological methods have been developed; however, most of them (enzyme-linked immunosorbent assay (ELISA) [17, 18], immunofluorescence antibody test (IFA) [19], and western blotting [20]) require sophisticated instruments, limiting their usages in healthcare environments. Moreover, these serological techniques have never been evaluated for the diagnosis of leishmaniasis in Thailand.

Molecular methods with great sensitivities and specificities have also been developed to diagnose leishmaniasis. One of the most classical techniques, polymerase chain reaction (PCR), is widely used [21-24]. However, the requirements for expensive equipment, DNA purification, and gel visualization have forestalled its utilization in field settings.

In 2000, Notomi et al. [25] developed the loopmediated isothermal amplification (LAMP) method. In short, this method uses several complex primers and a strand-displacement polymerase to achieve amplification. Though conceptually challenging, LAMP has several advantages over PCR from a field diagnostics point of view. 1) The reaction proceeds isothermally, thereby obviating the need for expensive thermal cyclers [25]. 2) Crude DNA extracts can be used directly without purification $[25,26] .3)$ The products can be detected visually using multiple parameters, including turbidity, fluorescence, and color.

Nevertheless, turbidity is challenging to discern and is unstable over time. Fluorescence measurement requires costly dyes (SYBR Green I [27], calcein [28], propidium iodide [29]) and is technically inconvenient due to its requirement for UV illumination. Due to their inhibitory effects, these dyes must be introduced post-reaction, increasing contamination risks. Colorimetric measurements are among the most straightforward of all of the detection methods. Several dyes have been reported to be useful, such as hydroxynaphthol blue (HNB) [30] and malachite green (MG) [31]. HNB requires the operator to distinguish between blue and violet, which can be ambiguous. In contrast, MG only requires distinction between blue and transparency.

LAMP has also been applied for the detection of $L$. infantum, both in dogs and humans [32, 33]. Pan-leishmania LAMP is also reported by Karani et al., Mikita et al. and Nzelu et al. [26, 31, 34]. However, Leishmania-specific colorimetric LAMP from clinical samples has never been described.Therefore, in this study, we developed a LAMP method using MG to detect Leishmania DNA from crude clinical samples. These data can be useful for the deployment of LAMP in field settings and can further enable detailed surveying of L. siamensis and L. martiniquensis in Thailand.

\section{Methods}

Primer design

To develop a pan-leishmania assay, we chose the highly conserved $18 \mathrm{~S}$ ribosomal RNA gene, as in previous panleishmania assays [26, 31, 34]. A consensus sequence was made from nine different Leishmania species, including L. tropica [GenBank: KF041809.1], L. martiniquensis [KJ467218.1], L. mexicana [KF041806.1], L. hertigi [KF041804.1], L. donovani [KF041801.1], L. chagasi (syn. L. infantum) [KF041797.1], L. infantum [KF302752.1], L. amazonensis [KF302746.1], and $L$. enriettii [KF041798.1]. However, L. siamensis was not included in this process due to the absence of its sequences on GenBank. The consensus sequence was imported into the PrimerExplorer version 4 software (http://primerexplorer.jp/elamp4.0.0/index.html), and primers were designed to avoid any mutations that were presented. To ensure optimality, primers with the lowest change in Gibb's free energy $(\Delta G)$ for dimer formation and the highest change in hybridization $\Delta G$ were chosen. The primers' thermodynamic properties were further validated using the OligoCalc software (http://www.basic.northwestern.edu/ biotools/oligocalc.html). A final verification of specificity was performed using Basic Local Alignment Search Tool (BLAST) (http://blast.ncbi.nlm.nih.gov/Blast.cgi) analysis against human DNA and any other organisms included in the differential diagnosis of leishmaniasis. The resulting primers are shown in Table 1 and Fig. 1, and were synthesized by BioDesign Co., Ltd, Pathumthani, Thailand.

\section{Quantitative polymerase chain reaction}

The $25 \mu$ reaction mixture contained $12.5 \mu \mathrm{l}$ of $2 \times$ reaction mix from the SuperScript ${ }^{\oplus}$ III Platinum ${ }^{\oplus}$ SYBR $^{\oplus}$ Green OneStep qRT-PCR Kit (Life Technologies, USA), $0.08 \mu \mathrm{M}$ of F3 primer, $0.08 \mu \mathrm{M}$ of $\mathrm{B} 3$ primers, and $1 \mathrm{U}$ of BIOTAQ ${ }^{\mathrm{rm}}$ DNA Polymerase (Bioline, Germany). The reaction was performed using the CFX96 ${ }^{\mathrm{Tm}}$ real-time PCR system (Bio-Rad 
Table 1 Primer sequences used in the study

\begin{tabular}{ll}
\hline Primer & Sequence $\left(5^{\prime} \rightarrow 3^{\prime}\right)$ \\
\hline FIP & GTCAAATTAAACCGCACGCTCCACGGGGGAGTACGTTCGCAA \\
$($ F1C-F2) & \\
BIP & TCAACACGGGGAACTITACCAGATCACCACCATTCAGGGAATCGA \\
$($ B1C-B2) & \\
F3 & CGAAAGCTTTGAGGTTACAGTCT \\
B3 & CAAACAAATCACTCCACCGAC \\
\hline
\end{tabular}

Laboratories, USA) and was programmed as followed: 3 min of initial denaturation at $95^{\circ} \mathrm{C}, 40$ cycles of denaturation at $95{ }^{\circ} \mathrm{C}$ for $20 \mathrm{sec}$, annealing at $50{ }^{\circ} \mathrm{C}$ for $30 \mathrm{sec}$, extension at $72{ }^{\circ} \mathrm{C}$ for $40 \mathrm{sec}$, and fluorescence data acquisition at $77{ }^{\circ} \mathrm{C}$. Upon completion, a final extension at $72{ }^{\circ} \mathrm{C}$ for 10 min ensued. The $\mathrm{C}_{\mathrm{q}}$ (quantification cycle) was defined to be 10 times the standard deviation of the baseline. A standard curve was generated using DNA dilutions in triplicates, and the efficiency was determined to be $98.44 \%$ with a linear range spanning 6 orders of magnitudes. Specificities of all samples were verified using melting curve analyses, which demonstrated a single peak at $83.5^{\circ} \mathrm{C}$.

\section{Loop-mediated isothermal amplification}

The LAMP reaction mixtures $(25 \mu \mathrm{l})$ were based on that described by Tomita et al. [28], which contained $1 \times$ Isothermal Amplification Buffer (New England Biolabs, USA), $8 \mathrm{mM} \mathrm{MgSO}_{4}, 0.8 \mathrm{M}$ Betaine (SigmaAldrich, USA), $1.4 \mathrm{mM}$ each of dATP, dCTP, dGTP, and dTTP (SibEnzyme, Russia), 40 pmol of FIP primer, 40 pmol of BIP primer, $10 \mathrm{pmol}$ of F3 primer, $10 \mathrm{pmol}$ of B3 primer, and $8 \mathrm{U}$ of Bst 2.0 WarmStart ${ }^{\circ}$ DNA Polymerase (New England Biolabs, USA). In addition, the colorimetric indicator, $0.008 \%$ MG (Sigma-Aldrich, USA) was added. The reaction was performed at $65^{\circ} \mathrm{C}$ for 75 min using the Veriti ${ }^{\bullet}$ 96-well Thermal Cycler (Life Technologies, USA).
Visualization of the LAMP products was performed using $2.5 \%$ agarose gel electrophoresis at $10 \mathrm{~V} / \mathrm{cm}$ in $1 \times$ TAE buffer.

\section{Promastigote culture}

L. siamensis isolate PCM2 and L. martiniquensis isolate CU1 were used in this study and were derived from bone marrow aspirates of infected patients. The culture media was Schneider's insect medium (Sigma-Aldrich, USA) supplemented with $10 \%$ fetal bovine serum, 100 $\mathrm{U}$ of penicillin (Sigma-Aldrich, USA), and $100 \mu \mathrm{g} / \mathrm{ml}$ streptomycin (Sigma-Aldrich, USA). The cultures were incubated at $25 \pm 2{ }^{\circ} \mathrm{C}$, and subculturing was done every $2-3$ days at a ratio of $1: 2$.

\section{Reference DNA}

All Leishmania DNA samples used in this study were extracted using the Invisorb ${ }^{\odot}$ Spin Tissue Mini Kit (Stratec Biomedical AG, Germany). While L. siamensis and $L$. martiniquensis DNA were derived from cell culturing, $L$. aethiopica, L. braziliensis, L. donovani, and L. tropica DNA were derived from tissue biopsies of patients with imported leishmaniasis. Trypanosoma brucei DNA was extracted from a permanent slide sample, while Trichomonas vaginalis and Giardia lamblia DNA were isolated from infected patient samples at King Chulalongkorn Memorial Hospital. All DNA samples were of sufficient quality, as indicated by their optimal 260/280 and 260/230 ratios.

\section{Detection limit}

To generate standard parasite concentrations and assess LAMP's tolerance to inhibitors that can be presented in the saliva, 10-fold dilutions of L. siamensis from $10^{7}-10^{0}$ parasites $/ \mathrm{ml}$ were made using either $1 \times$ phosphatebuffered saline (PBS) or human saliva. Each dilution was divided into two portions. One portion was extracted for
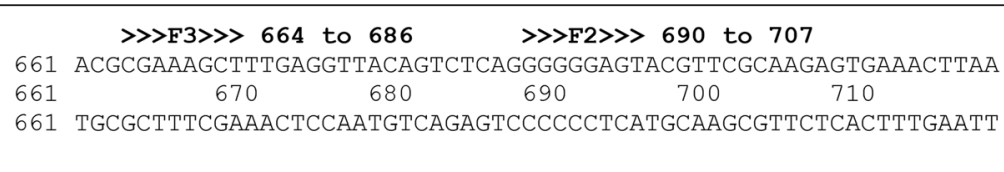

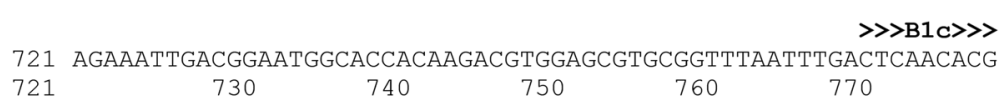

721 TCTTTAACTGCCTTACCGTGGTGTTCTGCACCTCGCACGCCAAATTAAACTGAGTTGTGC $\ll<F 1 C<<<749$ to 772

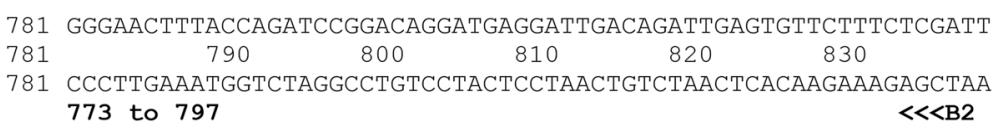

841 CCCTGAATGGTGGTGCATGGCCGCTTTTGGTCGGTGGAGTGATTTGTTTGGTTGATTCCG

$\begin{array}{rrrrr}841 & 850 & 860 & 870 & 880\end{array}$

841 GGGACTTACCACCACGTACCGGCGAAAACCAGCCACCTCACTAAACAAACCAACTAAGGC

$\ll<835$ to $854 \quad<<$ B $3<<870$ to 890

Fig. 1 Targeted Amplification Region on the 18S Ribosomal RNA Gene of L. martiniquensis (KJ467218.1) 
DNA using the Invisorb ${ }^{\circ}$ Spin Tissue Mini Kit (Stratec Biomedical AG, Germany), and the other was boiled at $100{ }^{\circ} \mathrm{C}$ for $10 \mathrm{~min}$, as described previously [26].

To simulate infected blood, $100 \mu$ dilutions of $L$. siamensis in human blood were made as described above and divided into two portions. The first portion was added with Triton X-100 to a final concentration of $1 \%$, and boiled at $100{ }^{\circ} \mathrm{C}$ for $10 \mathrm{~min}$, which resulted in a coagulum. Next, $50 \mu \mathrm{l}$ of $\mathrm{ddH}_{2} \mathrm{O}$ was added, and the coagulum was broken up by vigorous agitation with a pipette tip. The second portion was subjected to DNA extraction using the Invisorb ${ }^{\circ}$ Spin Blood DNA Mini Kit (Stratec Biomedical AG, Germany); $2.5 \mu \mathrm{l}$ of each resultant was directly introduced to both qPCR and LAMP.

\section{Clinical samples}

Peripheral blood and saliva were obtained from two patients.

Patient 1 was initially reported by Phumee et al. [35]. In short, the patient was a 49-year-old man who was HIV positive and presented with multiple nodules on his body. Microscopy and cell culturing revealed the presence of Leishmania parasites in the nodules, and molecular analysis confirmed L. martiniquensis infection [16]. He was successfully treated with amphotericin B and itraconazole. Blood, saliva, and tissue biopsy were obtained. The blood was treated in the same manner as described above, while the saliva and tissue biopsy (drenched in $1 \times \mathrm{PBS}$ ) were boiled at $100{ }^{\circ} \mathrm{C}$ for $10 \mathrm{~min}$. $2.5 \mu \mathrm{l}$ of the supernatant were used as the template.

Patient 2 was described by Chusri et al. [10]. He was a 30-year-old man who was HIV positive. Similar to Patient 1 , he had multiple papules on his skin, but this patient also had internal organ involvements. Leishmania parasites were microscopically confirmed to be infiltrating the bone marrow and ulcers. Further molecular data confirmed this Leishmania species to be L. martiniquensis [16]. He was also successfully treated with amphotericin B and itraconazole. Blood, saliva, and bone marrow biopsy were obtained. The saliva and blood was treated as described earlier, and the bone marrow biopsy was treated in the same manner as the blood.

\section{Ethical statement}

This study was approved by the Institutional Review Board on Human Research of the Faculty of Medicine, Chulalongkorn University (COA No. 725/2013).

\section{Results}

Both $\mathrm{qPCR}$ and LAMP successfully amplified regions that were specified by the newly designed primers. For LAMP, successful amplification was associated with MG's characteristic light blue color, whereas failed amplification was associated with transparency (Fig. 2). Gel electrophoresis of the LAMP products also exhibited their characteristic "mixture of stem-loop DNAs with various stem lengths, and cauliflower-like structures with multiple loops" [25], which further confirmed their successful amplifications.

The detection limits $\left(\log _{10}\right.$ parasites $\left./ \mathrm{ml}\right)$ of L. siamensis for LAMP, as defined by the appearance of its light blue color, and qPCR, as defined by fluorescence above the $\mathrm{C}_{\mathrm{t}}$, are shown in Table 2 .

For qPCR, our results indicated that the direct use of the samples was possible but was associated with increases in the detection limits. However, whole blood could not be used, due to the total inhibition of Taq polymerase.

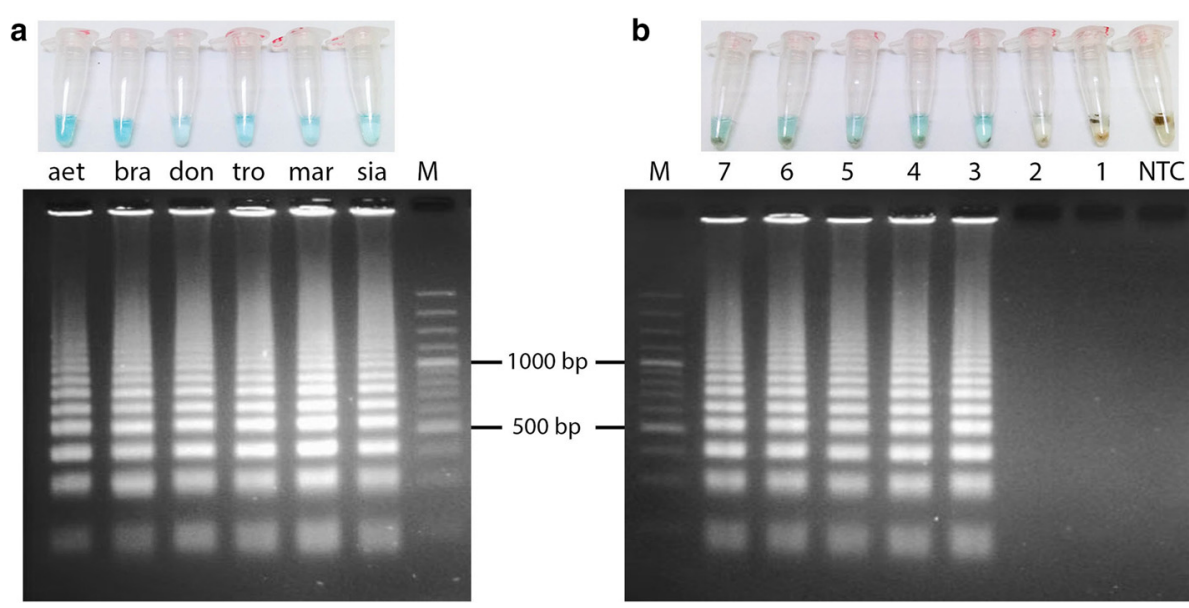

Fig. 2 Detection of LAMP Products by MG-based Colorimetric Changes and Gel Electrophoresis. a LAMP was able to detect multiple species of Leishmania. (aet $=$ L. aethiopica; bra $=$ L. braziliensis; don $=$ L. donovani; tro $=$ L. tropica; mar $=$ L. martiniquensis; sia $=$ L.siamensis) $\mathbf{b}$ LAMP could detect L. siamensis in the presence of whole blood. Ten-fold dilutions of L. siamensis in whole blood (log parasites/ml) were lysed, boiled, and subjected to LAMP. The black precipitates are coagulated blood 
Table 2 Detection limits of LAMP and qPCR under various conditions (log parasites $/ \mathrm{ml})\left(F^{*}=\right.$ Fail to amplify)

\begin{tabular}{llll}
\hline Diluent & Method & LAMP & qPCR \\
\hline 1X PBS & Boiled & 3 & 5 \\
& Extracted & 3 & 4 \\
Saliva & Boiled & 3 & 4 \\
& Extracted & 4 & 4 \\
Whole blood & Boiled & 3 & $F^{*}$ \\
& Extracted & 4 & 5 \\
\hline
\end{tabular}

In the case of LAMP, which is more tolerant of PCR inhibitors, removal of the extraction process allowed a lower detection limit of $10^{3}$ parasites $/ \mathrm{ml}$ across all samples. Crude samples did not affect the properties of MG as all of the positive samples displayed MG's characteristic color. The use of whole blood did shift the color toward a greenish tone, whereas the negative samples were yellow in color (Fig. 2). However, an excessive amount of whole blood or the presence of uncoagulated blood could prevent the discrimination between positive and negative results, as hemoglobin absorption spectrum overlapped that of MG.

Clinical samples also yielded useful information in microscopically diagnosed patients. Patient 1 , who had $\mathrm{CL}$, had detectable Leishmania DNA in his saliva and tissue biopsy. Patient 2, in contrast, who had CL and $\mathrm{VL}$, had the DNA presented in his bone marrow, blood, and saliva (Fig. 3).

\section{Discussion}

With an increasing number of cases, leishmaniasis is now an emerging infectious disease in Thailand. However, current diagnostic methods require experienced personnel, advanced facilities, and a large amount of time. Thus, simplification is now critical to bring diagnostics to point-of-care settings. Therefore, we developed the LAMP method to complement leishmaniasis diagnostic process and to facilitate epidemiological studies of leishmaniasis in Thailand.

Molecular techniques have exploited multiple genes to detect Leishmania, most of which are high-copy-number genes, including cysteine protease B [36], gp63 [37], internal transcribed spacer 1 (ITS1) [38], 18S ribosomal RNA [26, 31], and minicircle kinetoplast DNA [24]. As expected, comparative studies have shown that the minicircles, which have the highest copy number, yield the highest sensitivity $[39,40]$. However, minicircles are highly variable and due to LAMP's requirement of six conserved regions, it is not feasible to design panleishmania LAMP primers that target minicircles. In our approach, we chose the $18 \mathrm{~S}$ ribosomal RNA gene, which represents a balanced trade-off between copy number and variability. As Karani et al., Mikita et al. and Nzelu et al. recently reported, LAMP has been shown to detect most species of Leishmania [26, 31, 34]. Here, we also experimentally confirmed the detection of $L$. martiniquensis and L. siamensis. Our detection limit was comparable to that of Mikita et al. $\left(10^{3}\right.$ parasites $\left./ \mathrm{ml}\right)$, but was 10 -fold higher than that of Nzelu et al. $\left(10^{2}\right.$ parasites/ml) [26, 31].

We detected Leishmania DNA in the blood and bone marrow, and in the tissue and saliva of the VL and CL patient, respectively. Our findings agreed with others that Leishmania DNA can be found in multiple noninvasive sources, including saliva (CL, VL) [10, 12, 41], skin swabs (CL) [26] and peripheral blood (VL) [42, 43]. We recommend the use of multiple DNA sources to reduce the probability of false negatives.

Our results also suggested that LAMP could be used to detect Leishmania DNA from crude clinical samples without compromising the detection limit. Furthermore, the use of crude samples even lowered the detection limit by 10 -fold $\left(10^{3}\right.$ parasites $\left./ \mathrm{ml}\right)$, but the same could not be said with qPCR, which increased this limit by 10 fold. We suspected that in the case of LAMP, the removal of inhibitors did not compensate for the loss of

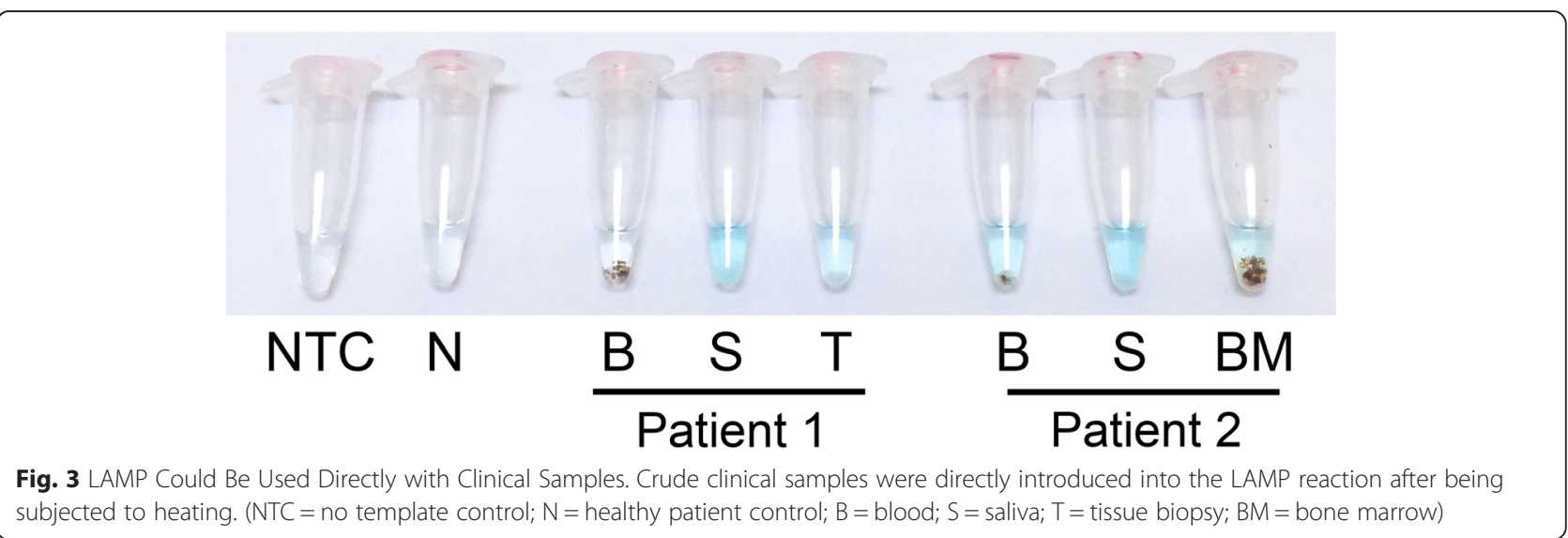


DNA from the extraction process, as in the case of qPCR. These results are in concordance with other studies that used boiled samples in LAMP [26, 44, 45]. In addition, of all of the DNA preparation methods compared, Sun et al. [46] reported that simple boiling results in the highest sensitivity.

Furthermore, the use of MG greatly facilitates the interpretation of results as it is highly discernable and consistent [31]. Because MG is inexpensive and can be stored at room temperature, this dye could tremendously increase the applicability of LAMP in the field.

Earlier attempts to couple direct blood samples with a colorimetric detection method were unsuccessful, due to the intense color of hemoglobin. To solve this problem, we induced the precipitation of the blood using its own coagulation system. We initially lysed the blood and its accompanying parasites with Triton $\mathrm{X}-100$ and then promoted coagulation by boiling the sample. After boiling the sample, the coagulum was pulverized using a pipette tip. From this approach, we could clearly distinguish the results using MG, even with $2.5 \mu \mathrm{l}$ of whole blood.

Because LAMP can be performed isothermally using a simple heat block, stable electricity is not required. Recently, using phase-change material, LaBarre et al. [47] developed a stable heat block that did not require electricity. Microfluidics lab-on-a-chip for LAMP has also been developed and has enabled highly multiplexed reactions and further simplification [48]. Moreover, Tanner et al. [49] reported that the LAMP reaction mixture can be left at $37^{\circ} \mathrm{C}$ for two hours without compromising the detection limit. LAMP mixtures have also been lyophilized with a reported storage time at room temperature of at least seven months [50].

Nevertheless, because of the low prevalence of leishmaniasis in Thailand, we could only obtain a small number of microscopically diagnosed patients. Future work in a statistically significant group of patients is required to warrant the performance of this method.

Also, LAMP is particularly prone to contamination due to the large amount of DNA that it can generate, and its capability to amplify minute amounts of DNA. During this study, we nevertheless encountered multiple contamination issues. Therefore, we recommend that post-amplification reaction mixtures should not be opened due to aerosolization risks, and that all proper precautions be taken [51]. To prevent false positive results, no template control and healthy patient control should also be used. We also tested our assay specificity with $T$. vaginalis and $G$. lamblia DNA, with satisfying results. However, our assay did cross-react with DNA from Trypanosoma sp., a closely related protozoon (data not shown). Nevertheless, as each protozoon has a distinct set of clinical presentations, this cross-reaction would not impose a significant risk of misdiagnosis.

\section{Conclusion}

Sensitive molecular techniques to diagnose leishmaniasis have been introduced; nevertheless, due to their complexities, they have not yet been in widespread use. However, as our results demonstrated, LAMP could be used with unpurified clinical samples without compromising sensitivity and specificity, and its results could be unambiguously interpreted using MG.

With the advent of LAMP, molecular techniques can now be seamlessly integrated with field diagnostics. We anticipate that this combination will be crucial for surveying and controlling leishmaniasis in Thailand. However, further evaluation with a large cohort of patients will be required before the assay can be confidently deployed.

\section{Abbreviations}

CL: Cutaneous leishmaniasis; DAT: Direct agglutination test; ELISA: Enzymelinked immunosorbent assay; ICT: Immunochromatographic test; IFA: Indirect fluorescence antibody; LAMP: Loop-mediated isothermal amplification; MCL: Mucocutaneous leishmaniasis; MG: Malachite green; qPCR: Quantitative polymerase chain reaction; VL: Visceral leishmaniasis.

\section{Competing interests}

We declare that we have no competing interests.

\section{Authors' contributions}

Designed the experiments, conducted molecular laboratory work, and wrote the manuscript: CS, AP, and PS. Sample Collection: CS, AP, MM, SL, and PS. All authors read and approved the final manuscript.

\section{Authors' information}

Mr. Chaichontat Sriworarat is a student at Bangkok Christian College.

\section{Acknowledgements}

This study was supported by the Thailand Research Fund and Chulalongkorn University (RSA 5780024), the National Science and Technology Development Agency (Thailand) for a Research Chair Grant.

\section{Author details}

'Bangkok Christian College, Bangkok 10500, Thailand. ${ }^{2}$ Department of Parasitology, Faculty of Medicine, Chulalongkorn University, Bangkok 10330,

Thailand. ${ }^{3}$ Department of Parasitology, Phramongkutklao College of Medicine, Bangkok 10400, Thailand. ${ }^{4}$ Excellence Center for Emerging Infectious Diseases, King Chulalongkorn Memorial Hospital, Thai Red Cross Society, Bangkok 10330, Thailand.

Received: 8 October 2015 Accepted: 10 November 2015

Published online: 14 November 2015

\section{References}

1. DesjeuX P. Leishmaniasis: current situation and new perspectives. Comp Immunol Microbiol Infect Dis. 2004;27(5):305-18. doi:10.1016/j.cimid.2004.03.004.

2. Pearson RD, Sousa AQ. Clinical spectrum of leishmaniasis. Clin Infect Dis. 1996;22(1):1-13

3. Reithinger R, Dujardin JC, Louzir H, Pirmez C, Alexander B, Brooker S. Cutaneous leishmaniasis. Lancet Infect Dis. 2007;7(9):581-96. doi:10.1016/ S1473-3099(07)70209-8.

4. David CV, Craft N. Cutaneous and mucocutaneous leishmaniasis. Dermatol Ther. 2009;22(6):491-502. doi:10.1111/j.1529-8019.2009.01272.x.

5. Yanik M, Gurel MS, Simsek Z, Kati M. The psychological impact of cutaneous leishmaniasis. Clin Exp Dermatol. 2004;29(5):464-7. doi:10.1111/j.1365-2230. 2004.01605.x.

6. Boelaert M, Criel B, Leeuwenburg J, Van Damme W, Le Ray D, Van der Stuyft P. Visceral leishmaniasis control: a public health perspective. Trans R Soc Trop Med Hyg. 2000;94(5):465-71 
7. Thisyakorn $U$, Jongwutiwes $S$, Vanichsetakul $P$, Lertsapcharoen P. Visceral leishmaniasis: the first indigenous case report in Thailand. Trans R Soc Trop Med Hyg. 1999;93(1):23-4.

8. Maharom P, Siripattanapipong S, Mungthin M, Naaglor T, Sukkawee R, Pudkorn $R$, et al. Visceral leishmaniasis caused by Leishmania infantum in Thailand. Southeast Asian J Trop Med Public Health. 2008;39(6):988-90.

9. Suankratay C, Suwanpimolkul G, Wilde H, Siriyasatien P. Autochthonous visceral leishmaniasis in a human immunodeficiency virus (HIV)-infected patient: the first in thailand and review of the literature. Am J Trop Med Hyg. 2010;82(1):4-8. doi:10.4269/ajtmh.2010.09-0434.

10. Chusri S, Hortiwakul T, Silpapojakul K, Siriyasatien P. Consecutive cutaneous and visceral leishmaniasis manifestations involving a novel Leishmania species in two HIV patients in Thailand. Am J Trop Med Hyg. 2012;87(1):76-80. doi:10.4269/ajtmh.2012.11-0749.

11. Bualert L, Charungkiattikul W, Thongsuksai P, Mungthin M, Siripattanapipong S, Khositnithikul R, et al. Autochthonous disseminated dermal and visceral leishmaniasis in an AIDS patient, southern Thailand, caused by Leishmania siamensis. Am J Trop Med Hyg. 2012;86(5):821-4. doi:10.4269/ajtmh.2012.11-0707.

12. Phumee A, Kraivichian K, Chusri S, Noppakun N, Vibhagool A, Sanprasert V, et al. Detection of Leishmania siamensis DNA in saliva by polymerase chain reaction. Am J Trop Med Hyg. 2013;89(5):899-905. doi:10.4269/ajtmh.12-0612.

13. Viriyavejakul $P$, Viravan $C$, Riganti M, Punpoowong B. Imported cutaneous leishmaniasis in Thailand. Southeast Asian J Trop Med Public Health. 1997;28(3):558-62.

14. Kattipathanapong P, Akaraphanth R, Krudsood S, Riganti M, Viriyavejakul P. The first reported case of autochthonous cutaneous leishmaniasis in Thailand. Southeast Asian J Trop Med Public Health. 2012;43(1):17-20.

15. Chiewchanvit S, Tovanabutra N, Jariyapan N, Bates MD, Mahanupab P, Chuamanochan $\mathrm{M}$ et al. Chronic generalized fibrotic skin lesions from disseminated leishmaniasis caused by Leishmania martiniquensis in two HIV-infected patients from northern Thailand. Br J Dermatol. 2015. doi:10.1111/bjd.13812.

16. Pothirat T, Tantiworawit A, Chaiwarith R, Jariyapan N, Wannasan A Siriyasatien $\mathrm{P}$, et al. First isolation of Leishmania from Northern Thailand: case report, identification as Leishmania martiniquensis and phylogenetic position within the Leishmania enriettii complex. PLoS Negl Trop Dis. 2014; 8(12):e3339. doi:10.1371/journal.pntd.0003339.

17. Baldelli B, Orfei AB, Fioretti DP, Polidori GA, Ambrosi M. Serological diagnosis of human leishmaniasis by ELISA (enzyme-linked immunosorbent assay). Parassitologia. 1978;20(1-3):91-9.

18. De Cock KM, Hodgen AN, Channon JY, Siongok TK, Lucas SB, Rees PH. Enzyme-linked immunosorbent assay (ELISA) for the diagnosis of visceral leishmaniasis in Kenya. J Infect Dis. 1985;151(4):750-2.

19. Badaro R, Reed SG, Carvalho EM. Immunofluorescent antibody test in American visceral leishmaniasis: sensitivity and specificity of different morphological forms of two Leishmania species. Am J Trop Med Hyg. 1983;32(3):480-4.

20. Bogdan C, Stosiek N, Fuchs H, Rollinghoff M, Solbach W. Detection of potentially diagnostic leishmanial antigens by western blot analysis of sera from patients with kala-azar or multilesional cutaneous leishmaniasis. J Infect Dis. 1990;162(6):1417-8.

21. Hitakarun A, Tan-Ariya P, Siripattanapipong S, Mungthin M, Piyaraj P, Naaglor T, et al. Comparison of PCR methods for detection of Leishmania siamensis infection. Parasit Vectors. 2014;7:458. doi:10.1186/s13071-014-0458-x.

22. Miranda A, Saldana A, Gonzalez K, Paz H, Santamaria G, Samudio F, et al. Evaluation of PCR for cutaneous leishmaniasis diagnosis and species identification using filter paper samples in Panama, Central America. Trans R Soc Trop Med Hyg. 2012;106(9):544-8. doi:10.1016/j.trstmh.2012.05.005.

23. Mouttaki T, Morales-Yuste M, Merino-Espinosa G, Chiheb S, Fellah H, MartinSanchez J, et al. Molecular diagnosis of cutaneous leishmaniasis and identification of the causative Leishmania species in Morocco by using three PCR-based assays. Parasit Vectors. 2014;7:420. doi:10.1186/1756-3305-7-420.

24. Weigle KA, Labrada LA, Lozano C, Santrich C, Barker DC. PCR-based diagnosis of acute and chronic cutaneous leishmaniasis caused by Leishmania (Viannia). J Clin Microbiol. 2002;40(2):601-6.

25. Notomi T, Okayama H, Masubuchi H, Yonekawa T, Watanabe K, Amino N, et al. Loop-mediated isothermal amplification of DNA. Nucleic Acids Res. 2000;28(12):E63.

26. Mikita K, Maeda T, Yoshikawa S, Ono T, Miyahira Y, Kawana A. The Direct Boil-LAMP method: a simple and rapid diagnostic method for cutaneous leishmaniasis. Parasitol Int. 2014;63(6):785-9. doi:10.1016/j.parint.2014.07.007.
27. Tsai SM, Chan KW, Hsu WL, Chang TJ, Wong ML, Wang CY. Development of a loop-mediated isothermal amplification for rapid detection of orf virus. J Virol Methods. 2009;157(2):200-4. doi:10.1016/j.jviromet.2009.01.003.

28. Tomita N, Mori Y, Kanda H, Notomi T. Loop-mediated isothermal amplification (LAMP) of gene sequences and simple visual detection of products. Nat Protoc. 2008;3(5):877-82. doi:10.1038/nprot.2008.57.

29. Hill J, Beriwal S, Chandra I, Paul VK, Kapil A, Singh T, et al. Loop-Mediated Isothermal Amplification Assay for Rapid Detection of Common Strains of Escherichia coli. J Clin Microbiol. 2008;46(8):2800-4.

30. Goto M, Honda E, Ogura A, Nomoto A, Hanaki K. Colorimetric detection of loop-mediated isothermal amplification reaction by using hydroxy naphthol blue. Biotechniques. 2009;46(3):167-72. doi:10.2144/000113072.

31. Nzelu CO, Gomez EA, Caceres AG, Sakurai T, Martini-Robles L, Uezato H, et al. Development of a loop-mediated isothermal amplification method for rapid mass-screening of sand flies for Leishmania infection. Acta Trop. 2014; 132:1-6. doi:10.1016/j.actatropica.2013.12.016.

32. Gao CH, Ding D, Wang JY, Steverding D, Wang X, Yang YT, et al. Development of a LAMP assay for detection of Leishmania infantum infection in dogs using conjunctival swab samples. Parasit Vectors. 2015;8: 370. doi:10.1186/s13071-015-0991-2.

33. Ghasemian M, Gharavi MJ, Akhlaghi L, Mohebali M, Meamar AR, Aryan E, et al. Development and Assessment of Loop-Mediated Isothermal Amplification (LAMP) Assay for the Diagnosis of Human Visceral Leishmaniasis in Iran. Iran J Parasitol. 2014;9(1):50-9.

34. Karani M, Sotiriadou I, Plutzer J, Karanis P. Bench-scale experiments for the development of a unified loop-mediated isothermal amplification (LAMP) assay for the in vitro diagnosis of Leishmania species' promastigotes. Epidemiol Infect. 2014;142(8):1671-7. doi:10.1017/S0950268813002677.

35. Phumee A, Chusri S, Kraivichian K, Wititsuwannakul J, Hortiwakul T, Thavara $U$, et al. Multiple cutaneous nodules in an HIV-infected patient. PLoS Negl Trop Dis. 2014;8(12):e3291. doi:10.1371/journal.pntd.0003291.

36. Chaouch M, Mhadhbi M, Adams ER, Schoone GJ, Limam S, Gharbi Z, et al. Development and evaluation of a loop-mediated isothermal amplification assay for rapid detection of Leishmania infantum in canine leishmaniasis based on cysteine protease B genes. Vet Parasitol. 2013;198(1-2):78-84. doi:10.1016/j.vetpar.2013.07.038

37. Guerbouj S, Djilani F, Bettaieb J, Lambson B, Diouani MF, Ben Salah A, et al. Evaluation of a gp63-PCR based assay as a molecular diagnosis tool in canine leishmaniasis in Tunisia. PLoS One. 2014;9(8):e105419. doi:10.1371/ journal.pone.0105419.

38. Ajaoud M, Es-sette N, Hamdi S, El-Idrissi AL, Riyad M, Lemrani M. Detection and molecular typing of Leishmania tropica from Phlebotomus sergenti and lesions of cutaneous leishmaniasis in an emerging focus of Morocco. Parasit Vectors. 2013;6:217. doi:10.1186/1756-3305-6-217.

39. Bensoussan E, Nasereddin A, Jonas F, Schnur LF, Jaffe CL. Comparison of PCR assays for diagnosis of cutaneous leishmaniasis. J Clin Microbiol. 2006; 44(4):1435-9. doi:10.1128/JCM.44.4.1435-1439.2006.

40. Yurchenko WY, Merzlyak EM, Kolesnikov AA, Martinkina LP, Vengerov YY. Structure of Leishmania minicircle kinetoplast DNA classes. J Clin Microbiol. 1999;37(5):1656-7.

41. Galai Y, Chabchoub N, Ben-Abid M, Ben-Abda I, Ben-Alaya-Bouafif N, Amri F, et al. Diagnosis of mediterranean visceral leishmaniasis by detection of leishmania antibodies and leishmania DNA in oral fluid samples collected using an Oracol device. J Clin Microbiol. 2011;49(9):3150-3. doi:10.1128/jcm.00267-11.

42. Antinori S, Calattini S, Longhi E, Bestetti G, Piolini R, Magni C, et al. Clinical use of polymerase chain reaction performed on peripheral blood and bone marrow samples for the diagnosis and monitoring of visceral leishmaniasis in HIV-infected and HIV-uninfected patients: a single-center, 8-year experience in Italy and review of the literature. Clin Infect Dis. 2007:44(12): 1602-10. doi:10.1086/518167.

43. Alborzi A, Pourabbas B, Shahian F, Mardaneh J, Pouladfar GR, Ziyaeyan M. Detection of Leishmania infantum kinetoplast DNA in the whole blood of asymptomatic individuals by PCR-ELISA and comparison with other infection markers in endemic areas, southern Iran. Am J Trop Med Hyg. 2008;79(6):839-42.

44. Njiru ZK. Rapid and sensitive detection of human African trypanosomiasis by loop-mediated isothermal amplification combined with a lateral-flow dipstick. Diagn Microbiol Infect Dis. 2011;69(2):205-9. doi:10.1016/j. diagmicrobio.2010.08.026.

45. Poon LL, Wong BW, Ma EH, Chan KH, Chow LM, Abeyewickreme W, et al. Sensitive and inexpensive molecular test for falciparum malaria: detecting Plasmodium falciparum DNA directly from heat-treated blood by loop- 
mediated isothermal amplification. Clin Chem. 2006;52(2):303-6. doi:10.1373/clinchem.2005.057901.

46. Sun $Y$, Zhao L, Zhao M, Zhu R, Deng J, Wang F, et al. Four DNA extraction methods used in loop-mediated isothermal amplification for rapid adenovirus detection. J Virol Methods. 2014;204:49-52. doi:10.1016/j. jviromet.2014.04.006

47. LaBarre P, Hawkins KR, Gerlach J, Wilmoth J, Beddoe A, Singleton J, et al. A simple, inexpensive device for nucleic acid amplification without electricity-toward instrument-free molecular diagnostics in low-resource settings. PLoS One. 2011;6(5):e19738. doi:10.1371/journal.pone.0019738

48. Fang $\mathrm{X}$, Liu Y, Kong J, Jiang X. Loop-mediated isothermal amplification integrated on microfluidic chips for point-of-care quantitative detection of pathogens. Anal Chem. 2010;82(7):3002-6. doi:10.1021/ac1000652.

49. Tanner NA, Zhang Y, Evans Jr TC. Simultaneous multiple target detection in real-time loop-mediated isothermal amplification. Biotechniques. 2012;53(2): 81-9. doi:10.2144/0000113902.

50. Hayashida K, Kajino K, Hachaambwa L, Namangala B, Sugimoto C. Direct blood dry LAMP: a rapid, stable, and easy diagnostic tool for Human African Trypanosomiasis. PLoS Negl Trop Dis. 2015;9(3):e0003578. doi:10.1371/ journal.pntd. 0003578

51. Champlot S, Berthelot C, Pruvost M, Bennett EA, Grange T, Geigl EM. An efficient multistrategy DNA decontamination procedure of $P C R$ reagents for hypersensitive PCR applications. PLoS One. 2010;5(9). doi:10.1371/journal.pone.0013042.

\section{Submit your next manuscript to BioMed Central and take full advantage of:}

- Convenient online submission

- Thorough peer review

- No space constraints or color figure charges

- Immediate publication on acceptance

- Inclusion in PubMed, CAS, Scopus and Google Scholar

- Research which is freely available for redistribution 